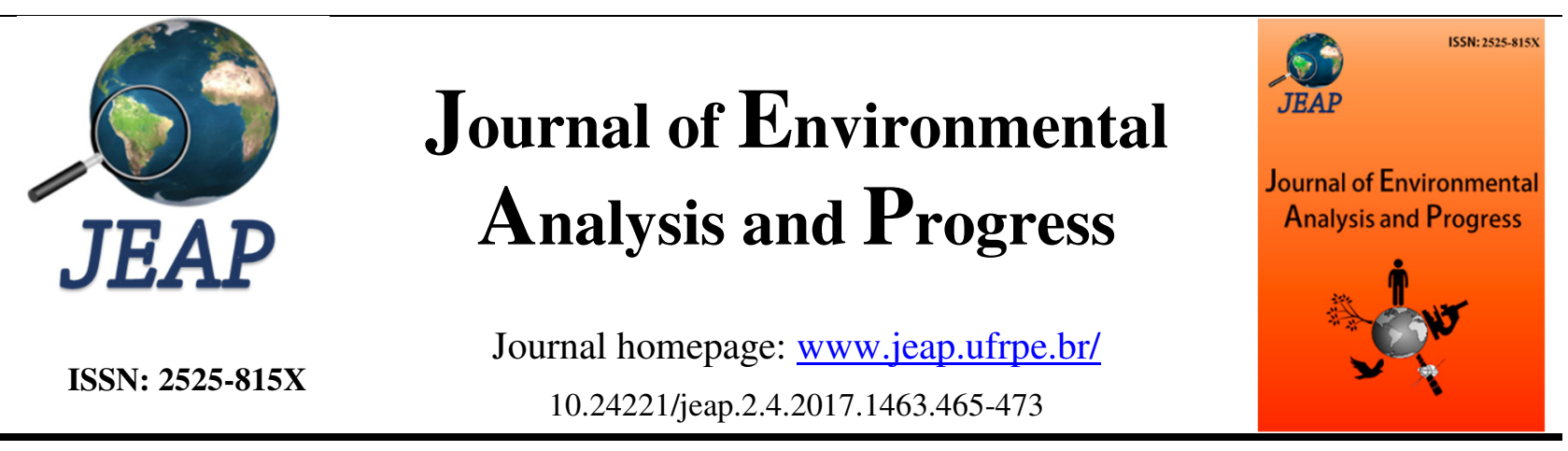

\title{
Período de retorno de eventos de precipitação favoráveis às culturas no estado de Alagoas
}

\section{Return period of favorable precipitation events to crops in the State of Alagoas}

Jaime Fernando António a , Manuel Agostinho Victor António a , André Luiz de Carvalho a , José Leonaldo de Souza ${ }^{\mathrm{a}}$, Fabrício Daniel dos Santos Silva ${ }^{\mathrm{a}}$

${ }^{a}$ Universidade Federal de Alagoas-UFAL, Av. Lourival Melo Mota, S/N, Tabuleiro do Martins, Maceió, Alagoas, Brasil. CEP: 57072-900. E-mail: jaimefernandoantonio@gmail.com; manuel.antonio@icat.ufal.br; del.andre2@gmail.com; leonaldojs@yahoo.com.br; fabricio.santos@icat.ufal.br.

\begin{tabular}{l}
\hline A R T I C L E I N F O \\
\hline Recebido 30 Jun 2017 \\
Aceito 08 Set 2017 \\
Publicado 21 Set 2017
\end{tabular}

\begin{abstract}
A B S T R A C T
The high variability of climatic conditions is the main factor responsible for the oscillations of crops in Brazil. These conditions have significantly influenced the development of the economic and agricultural sector in the State of Alagoas. The objective of this study was to determine the return period of precipitation events favorable to the development of crops within the growing season, in the State of Alagoas, considering the water availability by regional rainfall and crop water requirement by the evapotranspiration. Calculations of the sum of rainfall totals and reference evapotranspiration (ETo) were performed, using meteorological data obtained from INMET, ANA, SUDENE, and CPC. The ETo and precipitation data obtained for each region were spatialized for the whole State of Alagoas using QGIS software 2.14.2. The results have shown that potato and bean cultivation was satisfactory to a significant part of the State, and crops such as maize and rice were favorable only in the regions of Forest Zone, Litoral, and part of Agreste of Alagoas. Tomato cultivation did not present satisfactory conditions in almost all the regions. In this case, it is affirmed the need for implementation of irrigation systems for a more sustainable agricultural practice.
\end{abstract}

Keywords: Reference evapotranspiration, water requirement, water deficit.

\begin{abstract}
R E S U M O
A grande variabilidade das condições climáticas é tida como principal fator responsável pelas oscilações das safras agrícolas no Brasil. Estas condições têm influenciado de maneira significativa o desenvolvimento do setor econômico e agropecuário no estado de Alagoas. O objetivo desse estudo foi determinar o período de retorno de eventos de precipitações favoráveis ao desenvolvimento das culturas agrícolas dentro da estação de cultivo, para o estado de Alagoas, levando em conta a disponibilidade hídrica pela precipitação regional e a necessidade hídrica da cultura pela evapotranspiração. Foram realizados cálculos da soma dos totais das chuvas e a evapotranspiração de referência (ETo), utilizando dados meteorológicos obtidos do INMET, ANA, SUDENE e o CPC. Os dados de ETo e da precipitação obtidas para cada região foram espacializados para todo o estado de Alagoas, utilizando o software QGIS 2.14.2. Os resultados mostraram que o cultivo de batata e feijão foi satisfatório, em grande parte do estado, e culturas como milho e arroz foram favoráveis apenas nas regiões da Zona da Mata, Litoral e parte do Agreste alagoano. O cultivo de tomate não apresentou condições satisfatórias em quase todas as regiões. Com isso, afirma-se a necessidade de implementação de sistemas de irrigação para uma prática agrícola mais sustentável.
\end{abstract}


Palavras-Chave: Evapotranspiração de referência, necessidade hídrica, déficit hídrico.

\section{Introdução}

O estado de Alagoas tem como base econômica a agricultura, pecuária, a Indústria e o Turismo. No entanto, para o bom desenvolvimento das culturas agrícolas e das plantas em geral, dependem das condições de tempo e clima, da disponibilidade e distribuição dos recursos hídricos na região. As análises da produção agrícola mostram alta correlação entre variações de safras, das principais culturas, e as condições meteorológicas e climáticas (Monteiro, 2009).

As culturas agrícolas têm fenologia diferenciada que se relacionam com as exigências hídricas. Culturas agrícolas anuais, como arroz (Oryza sativa L.), feijão (Phaseolus vulgaris L.), milho (Zea mays $L$.) e tomate, apresentam três fases de desenvolvimento (vegetativa, reprodutiva e maturação), enquanto a cultura da batata doce (Ipomoea batatas L.) apresenta quatro fases (brotação, tuberização, vegetativa e senescência), sendo o ciclo médio de desenvolvimento dessas culturas compreendido entre 100 a 150 dias. Assim, a necessidade hídrica depende do tipo da cultura e varia com sua fase de desenvolvimento e duração (FAO, 2011). As culturas apresentam períodos críticos (sem deficiência de água), que para o milho vai da pré-floração ao início do enchimento dos grãos (Morizet \& Togola, 1984). Quando o déficit hídrico ocorre durante o período crítico dessa cultura, a produtividade é afetada, reduzindo, principalmente, o número de grãos por espiga (Bergonci et al., 2001; Doorenbos \& Pruitt, 1977).

Nessas condições, o uso da irrigação tornase fundamental, pois é no período crítico que ocorrem os maiores efeitos do déficit hídrico, mostrando a necessidade de uma maior eficiência do uso da irrigação. Para Doorenbos \& Kassan (1979), a necessidade hídrica da cultura do milho varia de 500 a $800 \mathrm{~mm}$, a do arroz varia de 500 a $950 \mathrm{~mm}$, a do feijão de 300 a $500 \mathrm{~mm}$, a da batata doce de 400 a $675 \mathrm{~mm}$ e a do tomate de $400 \mathrm{~mm}$ (regiões de clima úmido) a $600 \mathrm{~mm}$ (clima seco). Diante disso, objetivou-se determinar o período de retorno de eventos de precipitações favoráveis ao desenvolvimento das culturas agrícolas na estação de cultivo, levando em consideração a disponibilidade de água através da precipitação e a necessidade hídrica da cultura pela evapotranspiração.

\section{Material e Métodos}

Localização da região de estudo

Os locais de estudo estão representados na Tabela 1, localizados no Estado de Alagoas, na região Nordeste do Brasil (NEB), entre as latitudes $08^{\circ} 48^{\prime} \mathrm{S}$ e $10^{\circ} 29^{\prime} \mathrm{S}$ e longitudes $35^{\circ} 09^{\prime} \mathrm{W}$ e $38^{\circ}$ $13^{\prime}$ W. Essa região possui mais de um milhão de habitantes e é banhada, a leste, pelo Oceano Atlântico. Neste estudo, o estado foi subdividido em quatro regiões distintas, conforme as características climáticas de cada região (Sertão ou Interior, Agreste, Zona da Mata e Litoral).

Tabela 1. Locais (municípios) utilizados para espacialização da precipitação e evapotranspiração e cálculo do Período de Retorno no estado de Alagoas.

\begin{tabular}{|c|c|c|c|c|c|}
\hline Região & Localidade & Latitude & Longitude & Altitude (m) & $\begin{array}{l}\text { Período de } \\
\text { observação }\end{array}$ \\
\hline \multirow{7}{*}{ Interior } & Delmiro Gouveia & $09^{\circ} 23^{\prime} 19^{\prime \prime} \mathrm{S}$ & $37^{\circ} 59^{\prime} 57^{\prime \prime} \mathrm{W}$ & 256 & $1937-2016$ \\
\hline & Agua Branca & $09^{\circ} 15^{\prime} 39^{\prime \prime} \mathrm{S}$ & $37^{\circ} 56^{\prime} 10^{\prime \prime} \mathrm{W}$ & 560 & $1915-2016$ \\
\hline & Mata Grande & $09^{\circ} 07^{\prime} 03^{\prime \prime} \mathrm{S}$ & $37^{\circ} 43^{\prime} 56^{\prime \prime} \mathrm{W}$ & 633 & $1965-2000$ \\
\hline & $\begin{array}{c}\text { Olho D' Agua do } \\
\text { Casado }\end{array}$ & $09^{\circ} 30^{\prime} 07^{\prime} ' \mathrm{~S}$ & $37^{\circ} 50^{\prime} 02^{\prime \prime} \mathrm{W}$ & 209 & $1963-1999$ \\
\hline & Piranhas & $09^{\circ} 37^{\prime} 25^{\prime \prime} \mathrm{S}$ & $37^{\circ} 45^{\prime} 24^{\prime \prime} \mathrm{W}$ & 110 & $1913-2013$ \\
\hline & Pão de Açúcar & $09^{\circ} 44^{\prime} 54^{\prime \prime} \mathrm{S}$ & $37^{\circ} 26^{\prime} 12^{\prime \prime} \mathrm{W}$ & 45 & $1913-2010$ \\
\hline & Major Isidoro & $09^{\circ} 31^{\prime} 56^{\prime}, \mathrm{S}$ & $36^{\circ} 59^{\prime} 06^{\prime}, \mathrm{W}$ & 217 & $1915-1989$ \\
\hline \multirow{6}{*}{ Agreste } & Porto Real do Colégio & $10^{\circ} 11,09, \mathrm{~S}$ & $36^{\circ} 50,24, ’ \mathrm{~W}$ & 30 & $1921-1997$ \\
\hline & Palmeira dos Índios & $09^{\circ} 24^{\prime} 26^{\prime \prime} \mathrm{S}$ & $36^{\circ} 37^{\prime} 39^{\prime \prime} \mathrm{W}$ & 342 & $1913-2016$ \\
\hline & Quebrangulo & $09^{\circ} 19^{\prime} 08^{\prime \prime} \mathrm{S}$ & $36^{\circ} 28^{\prime} 16^{\prime \prime} \mathrm{W}$ & 411 & $1913-2013$ \\
\hline & Limoeiro de Anadia & $09^{\circ} 44^{\prime} 26^{\prime \prime} \mathrm{S}$ & $36^{\circ} 30^{\prime} 10^{\prime \prime} \mathrm{W}$ & 150 & $1913-2000$ \\
\hline & Mar Vermelho & $09^{\circ} 26^{\prime} 51^{\prime \prime} \mathrm{S}$ & $36^{\circ} 23^{\prime} 17^{\prime \prime} \mathrm{W}$ & 620 & $1963-2000$ \\
\hline & Traipu & $09^{\circ} 58^{\prime} 14^{\prime \prime} \mathrm{S}$ & $37^{\circ} 00^{\prime} 12^{\prime \prime} \mathrm{W}$ & 40 & $1913-2013$ \\
\hline \multirow{3}{*}{ Litoral } & Penedo & $10^{\circ} 17,25 ; \mathrm{S}$ & $36^{\circ} 35^{\prime} 11,, \mathrm{~W}$ & 28 & $1913-2013$ \\
\hline & Piaçabuçu & $10^{\circ} 24^{\prime} 20^{\prime} \mathrm{S}$ & $36^{\circ} 26^{\prime} 04^{\prime \prime} \mathrm{W}$ & 10 & $1944-2013$ \\
\hline & Coruripe & $10^{\circ} 07^{\prime} 32^{\prime \prime} \mathrm{S}$ & $36^{\circ} 10^{\prime} 32^{\prime \prime} \mathrm{W}$ & 10 & $1937-2013$ \\
\hline
\end{tabular}


Journal of Environmental Analysis and Progress V. 02 N. 04 (2017) 465-473

\begin{tabular}{|c|c|c|c|c|c|}
\hline & Maceió & $09^{\circ} 39^{\prime} 57^{\prime \prime} \mathrm{S}$ & $35^{\circ} 44^{\prime} 07^{\prime \prime} \mathrm{W}$ & 30 & $1913-2016$ \\
\hline & Porto de Pedra & $09^{\circ} 09^{\prime} 30^{\prime \prime} \mathrm{S}$ & $35^{\circ} 17^{\prime} 42^{\prime \prime} \mathrm{W}$ & 57 & $1938-2016$ \\
\hline \multirow{9}{*}{$\begin{array}{c}\text { Zona da } \\
\text { Mata }\end{array}$} & Anadia & $09^{\circ} 4104,3$ & $36^{\circ} 18,15, \cdots$ & 105 & $1913-2000$ \\
\hline & Vicosa & $09^{\circ} 22$ '17's $\mathrm{S}$ & $36^{\circ} 14^{\prime} 27^{\prime \prime} \mathrm{W}$ & 300 & $1913-2013$ \\
\hline & Santana do Mundaú & $09^{\circ} 10^{\prime} 05^{\prime} \mathrm{S}$ & $36^{\circ} 13^{\prime} 20^{\prime \prime} \mathrm{W}$ & 221 & $1963-2013$ \\
\hline & Atalaia & $09^{\circ} 30^{\prime} 07^{\prime} \mathrm{S}$ & $36^{\circ} 01^{\prime} 22^{\prime \prime} \mathrm{W}$ & 54 & $1914-2013$ \\
\hline & Capela & $09^{\circ} 24^{\prime} 27^{\prime \prime} \mathrm{S}$ & $36^{\circ} 04^{\prime} 25^{\prime}, \mathrm{W}$ & 34 & $1963-2000$ \\
\hline & União dos Palmares & $09^{\circ} 09^{\prime} 46^{\prime \prime} \mathrm{S}$ & $36^{\circ} 01^{\prime} 55^{\prime \prime} \mathrm{W}$ & 155 & $1913-2012$ \\
\hline & Rio Largo & $09^{\circ} 28^{\prime} 42^{\prime \prime} \mathrm{S}$ & $35^{\circ} 51^{\prime} 12^{\prime \prime} \mathrm{W}$ & 127 & $1972-2008$ \\
\hline & Flexeiras & $09^{\circ} 11^{\prime} 51^{\prime \prime} \mathrm{S}$ & $35^{\circ} 46^{\prime} 51^{\prime \prime} \mathrm{W}$ & 70 & $1963-2000$ \\
\hline & Matriz de Camaragibe & $09^{\circ} 09^{\prime} 06^{\prime \prime} \mathrm{S}$ & $35^{\circ} 32^{\prime} 00^{\prime \prime} \mathrm{W}$ & 16 & $1963-2000$ \\
\hline
\end{tabular}

\section{Descrição dos dados}

Foram utilizados dados diários de temperatura, umidade relativa e velocidade do vento de cinco estações meteorológicas convencionais cedidos pelo Instituto Nacional de Meteorologia

(INMET) (http://www.inmet.gov.br/portal/) para o período de 1961 a 2016, e dados de precipitação de 27 locais (para que se tenha uma melhor caracterização das chuvas dentro do Estado nas quatro regiões, ver Tabela 1) no período de 1913 a 2016 provenientes de registros da Superintendência de Desenvolvimento do Nordeste (SUDENE), Agencia Nacional de Águas (ANA) e Instituto Nacional de Meteorologia (Inmet) obtidos no Sistema de Informação Hidrológica-Hidroweb de livre acesso em (http://hidroweb.ana.gov.br/default.asp)

gerenciado pela Agencia Nacional de Água (ANA). As Figuras 1 e 2 foram obtidas usando o software de georreferenciamento geográfico Qgis.

Os dados das estações do INMET tiveram falhas preenchidas utilizando a técnica estatística Multivariate Imputation by Chained Equations (MICE) disponível como pacote em linguagem R, usando dados de referência oriundos de análises gradeadas com resolução espacial de $0,5^{\circ} \times 0,5^{\circ}$ provenientes do Climate Prediction Center (CPC) para precipitação (Chen et al., 2008; Silva et al., 2007) e de reanálises do National Center for Environmental Prediction/ National Center for Atmospheric Research (NCEP/NCAR), para as demais variáveis de superfície (Sheffield et al., 2006). As falhas nas séries temporais são caracterizadas por "NA", tais séries são confrontadas com as séries de referência usando-se o método Predictive Mean Matching (PM) para a geração de conjuntos com imputações múltiplas para os dados faltantes. Tais conjuntos de dados são comparados as séries de referência, sendo escolhido o conjunto que apresenta os menores erros para a imputação dos dados faltantes da série original (Van Buuren \& Groothuis-Oudshoorn, 2011).
Os dados diários foram transformados em valores médios decendiais sequenciais para as quatro regiões geográficas delimitadas para o estado. Assim, cada mês tem o decêndio 1 entre o $1^{\circ}$ ao $10^{\circ}$ dia, o decêndio 2 entre o $11^{\circ}$ ao $20^{\circ}$ dia e o decêndio 3 contendo do $21^{\circ}$ ao $28^{\circ}, 30^{\circ}$ ou $31^{\circ}$ dia, totalizando 36 decêndios no ano. Como exemplo, tem-se o mês de janeiro com os decêndios 1,2 e 3 e o de dezembro, com os decêndios 34, 35 e 36. Em seguida, foi calculada a Evapotranspiração de referência (ETo) pelo método de Penman-Monteith como recomendado pela Food and Agriculture Organization of the United Nations (FAO), permitindo encontrar a demanda de ETo da região e indicar a necessidade hídrica de diferentes culturas (Allen et al., 1998). Em uma região com demanda de ETo entre 2,5 a 5 mm.dia ${ }^{-1}$ (moderada), pode-se usar a evapotranspiração da cultura (ETc) $300 \mathrm{~mm}$ para feijão, $400 \mathrm{~mm}$ para batata, para o milho e arroz de $500 \mathrm{~mm}$, e $600 \mathrm{~mm}$ para o tomate, (Allen et al., 1998; Doorenbos \& Kassan, 1979). E por fim, foram gerados gráficos do período de retorno de precipitações favoráveis ao desenvolvimento da cultura na estação de cultivo, para dez locais do Estado de Alagoas (Tabela 2 e Figura 3) de abril a julho, para as culturas do milho, batata e arroz com ciclo médio de 120 dias, feijão com ciclo médio de 90 dias, e tomate com ciclo médio 150 dias, (Dooorenbos \& Kassan, 1979). A estação de cultivo no Estado, varia de região em região indo do segundo ao terceiro decêndio de março ao final de julho na região do Sertão e de início de abril ao final de agosto para as demais regiões, mais detalhes em (Cardim, 2003; Souza et. Al., 2015). Mas neste trabalho, usou-se como sendo do início de abril ao final de julho.

\section{Evapotranspiração de referência}

A equação de Penman-Monteith leva em consideração as equações de resistência aerodinâmica (ra) e resistência total da superfície (rs) aos movimentos turbulentos de transferência do vapor d'água, combinadas a fim de descrever uma vegetação hipotética de referência. 
Combinando expressões generalizadas de densidade do ar $(\rho)$ com expressões simplificadas de ra e rs para a grama, Allen et al. (1986), Smith et al. (1991) e Allen et al. (1994) reduziram a Equação de Penman-Monteith a:

ETo $=\frac{[\Delta *(\mathrm{Rn}-\mathrm{G})] / \lambda+[\gamma * 900 * \mathrm{U} 2 *(\mathrm{es}-\mathrm{ea})] /(\mathrm{T}+273)}{\Delta+\gamma *(1+0.34 * \mathrm{U} 2)}$

onde Rn e G são o saldo de radiação e o fluxo de calor no solo $\left(\mathrm{MJ} \cdot \mathrm{m}^{2} \cdot \mathrm{dia}^{-1}\right)$, $\mathrm{T}$ é a temperatura média diária $\left({ }^{\circ} \mathrm{C}\right), \mathrm{U}_{2}$ é a velocidade média do vento medida a $2 \mathrm{~m}$ de altura $(\mathrm{m} / \mathrm{s}), \lambda$ é o calor latente de evaporação da água igual a 2,45 (MJ.kg$\left.{ }^{1}\right), \Delta$ é a declividade da curva de pressão de vapor contra temperatura $\left(\mathrm{kPa} /{ }^{\circ} \mathrm{C}\right), \gamma$ é a constante psicrométrica $\left(\mathrm{kPa} /{ }^{\circ} \mathrm{C}\right)$, (es - ea) é o déficit de pressão de vapor do ar para altura de referência medida e 900 é um coeficiente para a cultura de referência $\left(\mathrm{kJ}^{-1} \cdot \mathrm{kg} \cdot \mathrm{K} \cdot \mathrm{d}^{-1}\right)$.

\section{Período de retorno}

Segundo Raimundo (2011), o período de retorno corresponde ao intervalo de tempo estimado para a ocorrência de determinado evento. Para o estudo estatístico da distribuição da probabilidade dos eventos desejados (estimar o tempo de retorno da chuva favorável à determinadas culturas), utilizou-se a técnica de Distribuição Assintótica dos Extremos do tipo I, também conhecido como distribuição de Gumbel, como mostrado por Oliveira (2011) e Tucci (2002).

A Função Probabilidade é dada por:

$P=e^{-e^{-\alpha(\mathrm{y}-\mu)}}$

onde, $\alpha$ o parâmetro de escala, $\mu$ o parâmetro de locação da distribuição e y o valor da chuva. $\alpha=1,2828 / s$ e $\mu=x-0,451 s$

onde $s$ o desvio padrão e $x$ a média.

Assumindo a função Tempo de Retorno (Tr) como:

$\operatorname{Tr}=1 /(1-\mathrm{P})$

Não menos importante, é destacar que para a espacialização da ETo utilizado, fez-se mediante os dados calculados dos cinco locais das estações do INMET, escolhendo como referência um local para cada região, como por exemplo, Pão de Açúcar para os outros locais localizados na região do Sertão sem a disponibilidade de todos os dados para o cálculo da ETo. Ainda na região do Sertão, usou-se valor de ETo de Água Branca em Mata Grande por apresentarem as mesmas características topográficas e climatológicas quanto a temperatura, chuvas e umidade. Maceió para o Litoral, Piaçabuçu nos locais mais ao Sul da região e Porto de Pedra ao Norte. Na região do Agreste usou-se os dados de Palmeira dos Índios e na Zona da Mata uma média obtida dos valores dos locais mais próximo (Maceió e Palmeira dos Índios).

\section{Resultados}

Observou-se na Figura 1 a distribuição das chuvas ao longo do Estado durante a estação de cultivo (abril a julho). Notou-se que a região do sertão apresenta regime pluviométrico inferior a $500 \mathrm{~mm}$, com destaque aos municípios do Delmiro Gouveia e Pão de Açúcar, com total de chuva muito abaixo, que dificilmente chega a $300 \mathrm{~mm}$. Dentre os municípios localizados no Sertão, apenas Agua Branca, Mata Grande e parte mais ao norte da região apresentam precipitações acima de $500 \mathrm{~mm}$, podendo atingir $550 \mathrm{~mm}$.

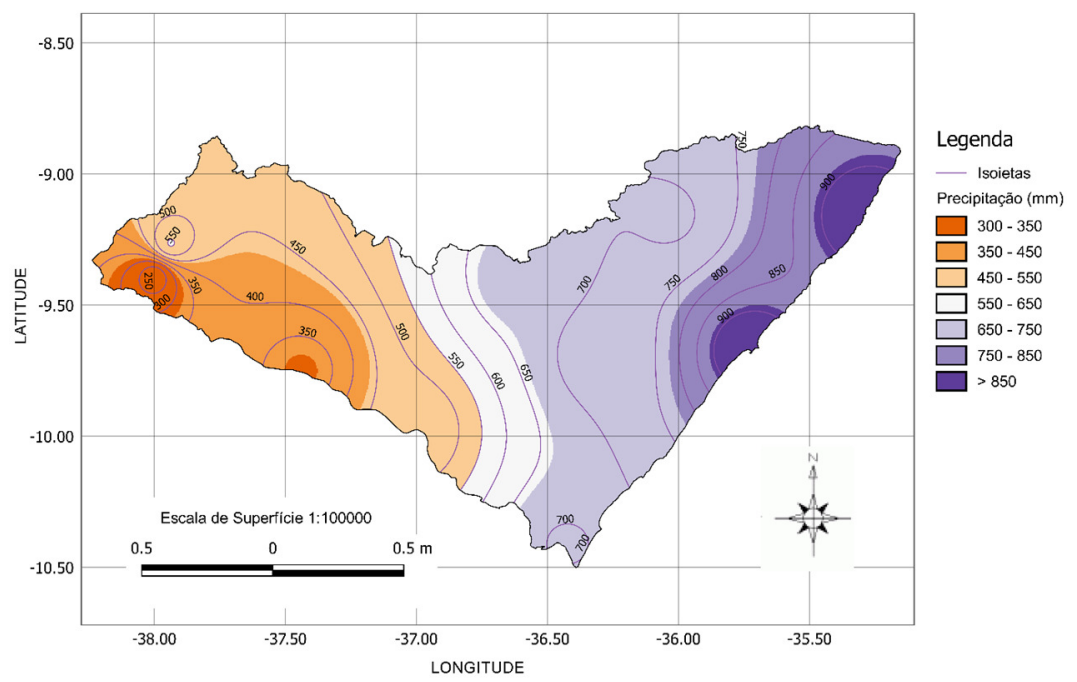

Figura 1. Precipitação total média durante a estação de cultivo no estado de Alagoas, no período entre 1913 e 2016. 
As localidades situadas no Agreste, o total pluviométrico observado foi de 550 a $650 \mathrm{~mm}$. Nas regiões da Zona da Mata e Litoral a precipitação variou de 750 a $850 \mathrm{~mm}$ atingindo valores superiores nos municípios tais como: Maceió, Porto de Pedras localizadas no litoral, e Flexeiras na Zona da Mata.

Quanto à evapotranspiração de referência (ETo) (Figura 2), observou-se que, em média, a evapotranspiração do estado é de $5 \mathrm{~mm} \cdot \operatorname{dia}^{-1}$, o que permitiu uma demanda de evapotranspiração de cerca de 540 a $600 \mathrm{~mm}$ em quase todas as regiões do estado. Entre todas as regiões, o Sertão apresentou maiores valores de ETo variando de 560 a $600 \mathrm{~mm}$, com exceção de Água Branca, situada mais a Noroeste da região (Sertão) que apresentou uma demanda inferior a $500 \mathrm{~mm}$ durante a estação de cultivo, a menor dentro da região (Sertão). Para a região da Zona da Mata, grande parte dela e o norte do Agreste, apresentaram ETo entre 500 a $540 \mathrm{~mm}$. Quanto ao Litoral, observou-se uma homogeneidade nos valores de ETo (de 540 a $560 \mathrm{~mm}$ ) (Figura 2).

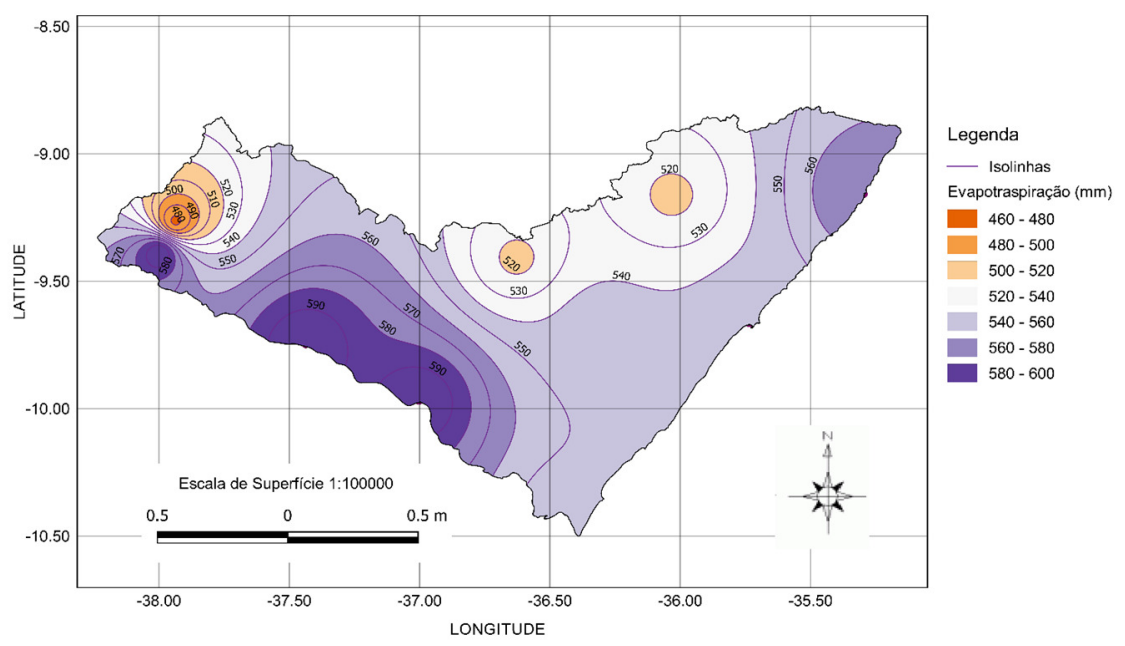

Figura 2. Evapotranspiração total média durante a estação de cultivo no estado de Alagoas, no período entre 1961 e 2016.

Na Tabela 2 observou-se as probabilidades de ocorrência de período de retorno para as respetivas cidades, Água Branca foi a única cidade do sertão que apresentou uma condição favorável ao cultivo do milho com probabilidade de $54 \%$ de retorno de precipitação acima de $500 \mathrm{~mm}$ dentro da estação de cultivo, $73 \%$ para o feijão e $72 \%$ para a Batata.

As cidades de Delmiro Gouveia e Pão de Açúcar não apresentaram condições favoráveis para o cultivo, ou seja, para a prática da atividade agrícola, seria necessária a implementação de um sistema de irrigação. Traipu apresentou apenas mínimas condições para o cultivo do feijão e batata, mas com uma probabilidade de sucesso que não ultrapassa os 50\%. Na região do Sertão, isto é, para as localidades analisadas, nenhuma presentou condições favoráveis para o cultivo de tomate e arroz sem o uso da irrigação. As demais localidades analisadas, Palmeiras dos Índios (Agreste) e Porto de Pedras (Litoral), apresentaram condições favoráveis para o cultivo do milho, feijão e batata, com probabilidade de sucesso superior a $75 \%$. Entre as localidades analisadas, apenas Maceió e Porto de Pedras apresentaram características favoráveis para o cultivo de tomate e arroz, sendo esta última (arroz), com até 54\% de sucesso, ou seja, seria necessário a implementação de um sistema de irrigação para obter uma melhor produtividade.

Tabela 2. Probabilidade de retorno de precipitação favorável para culturas agrícolas na estação de cultivo no Estado de Alagoas.

\begin{tabular}{lccccc}
\hline Cidades & & & Culturas $(\%)$ & & \\
& Milho & Feijão & Batata & Tomate & Arroz \\
\hline Delmiro Gouveia & 2 & 18 & 6 & 0 & 2 \\
Água Branca & 54 & 93 & 76 & 34 & 54 \\
Pão de Açúcar & 13 & 24 & 23 & 3 & 13 \\
Traipu & 35 & 50 & 49 & 12 & 35 \\
Palmeira dos Índios & 76 & 89 & 89 & 37 & 76 \\
Piaçabuçu & 89 & 98 & 98 & 40 & 89
\end{tabular}


Journal of Environmental Analysis and Progress V. 02 N. 04 (2017) 465-473

\begin{tabular}{lccccc} 
Anadia & 88 & 97 & 97 & 44 & 88 \\
União dos Palmares & 81 & 93 & 93 & 39 & 81 \\
Maceió & 95 & 98 & 98 & 93 & 95 \\
Porto de Pedra & 93 & 97 & 97 & 71 & 93 \\
\hline $\begin{array}{l}\text { Necessidade hídrica - } \\
\begin{array}{l}\text { Evapotranspiração da } \\
\text { cultura (ETc) }\end{array}\end{array}$ & $500 \mathrm{~mm}$ & $300 \mathrm{~mm}$ & $400 \mathrm{~mm}$ & $600 \mathrm{~mm}$ & $500 \mathrm{~mm}$ \\
\hline
\end{tabular}

O período de retorno de precipitação acima da necessidade hídrica de cada cultura foi agrupado em função das cidades tendo como objetivo determinar as regiões que apresentam disponibilidade hídricas favoráveis para o cultivo das culturas de milho, feijão, batata, tomate e arroz. Entre todas as localidades, destaca-se Delmiro Gouveia que apresentou período de retorno superior a 50 anos, sendo, aproximadamente, 18 anos para o cultivo da batata (necessidade hídrica acima de $400 \mathrm{~mm}$ ), 6 anos para o feijão (necessidade hídrica acima de $300 \mathrm{~mm}$ ) e 60 anos para o milho com necessidade hídrica acima de 500 $\mathrm{mm}$, não sendo mostrado o período de retorno para a cultura de tomate e arroz por apresentarem períodos de retornos muito elevado (superior a 100 anos), ou seja, 202 anos para precipitação acima de
$600 \mathrm{~mm}$ (necessidade hídrica para o tomateiro), no entanto sem chances de ser observado $(0 \%)$ nos próximos 100 anos, o arroz, apresentou os mesmos resultados observados nas analise feitas para o milho. As cidades de Pão de Açúcar e Traipu apresentaram um período de retorno compreendido entre 2,5 a 7 anos para precipitações que suprem a necessidade hídrica das culturas do milho, batata e feijão, acima $500 \mathrm{~mm}, 400 \mathrm{~mm}$ e $300 \mathrm{~mm}$, respectivamente (Figura 3).

Vale ressaltar que as regiões em que as condições para o cultivo foram favoráveis, como é o caso de Maceió, União dos Palmares, Porto de Pedra, Piaçabuçu Anadia e Palmeira dos Índios apresentaram períodos de retorno anual (todos os anos é verificado), com exceção da Água Branca, podendo atingir 3 anos para $600 \mathrm{~mm}$.

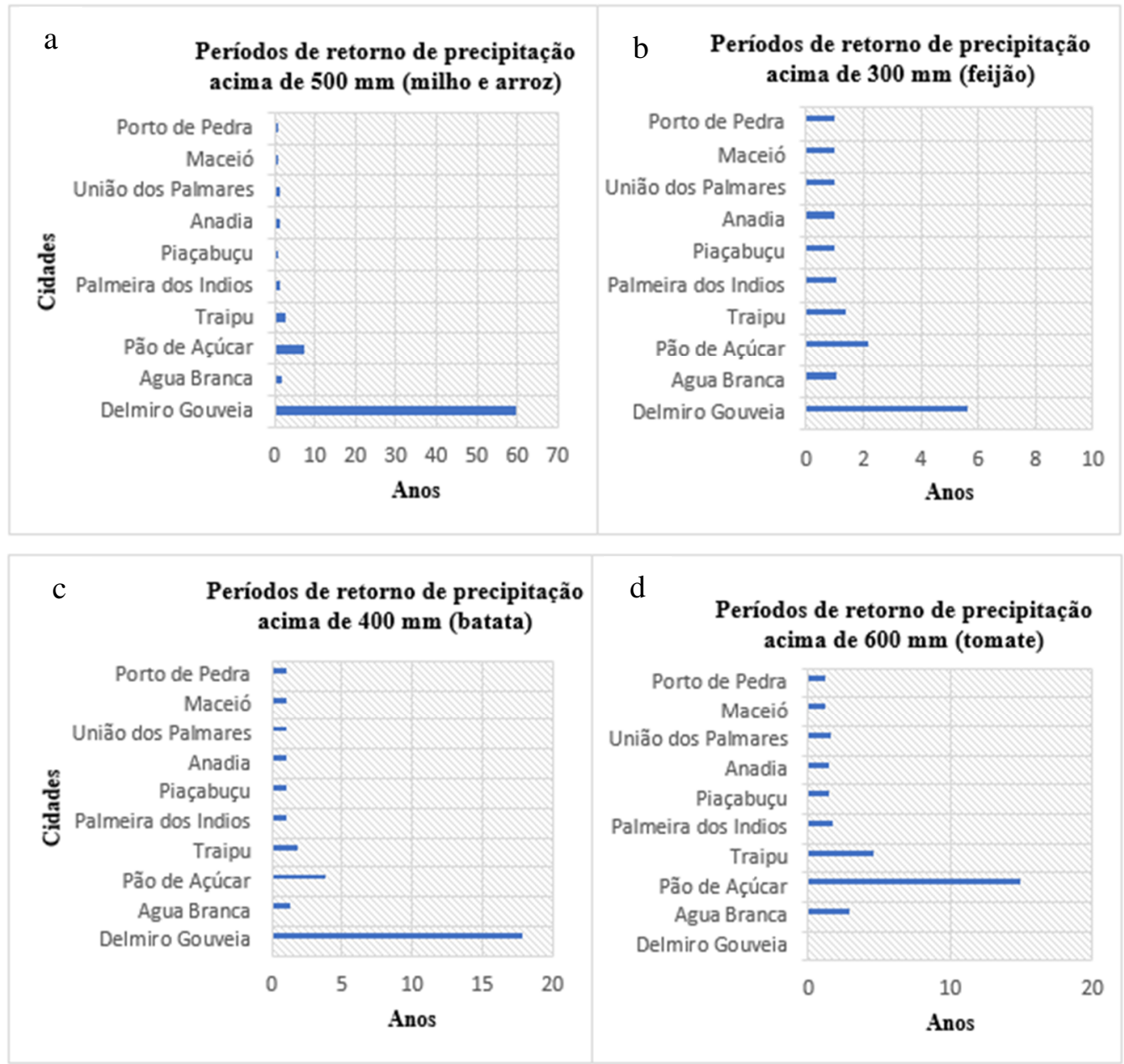

Figura 3. Períodos de retorno para as culturas do milho, feijão e arroz. a e b. batata doce e tomate; c e d. na estação de cultivo no estado de Alagoas, no período entre 1961 e 2016. 
Como observado na Figura 3, dentre as localidades situadas no Sertão do Estado, apenas Água Branca apresenta características de existência de disponibilidade de água para o cultivo do milho, feijão e batata, não apresentando por tanto, condições para o cultivo do tomate. Considerando as demais localidades, apenas Porto de Pedra e Maceió (Litoral), Piaçabuçu e Anadia (Zona da Mata), apresentaram condições favoráveis para o cultivo de tomate.

\section{Discussão}

Os resultados mostram regimes de precipitação influenciada pela topografia dentro da região do Sertão. Os municípios como Água Branca e Mata Grande apresentam topografias elevadas (regiões de altitudes elevadas), fazendo com que as massas de ar úmido vindo do oceano, ao passar sobre essas localidades sejam forcadas a ascender e se condensarem, provocando assim grandes volumes de chuvas nessas localidades.

Em 2002, Molion \& Bernardo observaram que as variabilidades na ocorrência de chuvas no Nordeste Brasileiro (NEB), e em particular no estado de Alagoas é devido a influência de diversos sistemas meteorológicos de meso e microescala, escalas sazonais e intra-sazonais, como por exemplo, os sistemas frontais e a Zona de Convergência Intertropical (ZCIT), Perturbações Ondulatórias dos Alísios (POA), complexos convectivos, as brisas (terrestres e marítimas) na mesorregião da Zona da Mata e Litoral.

Papel importante nas precipitações sobre o NEB também são atribuídos aos Anticiclones Subtropical do Atlântico Sul (ASAS), que transportam umidade do oceano para o continente, intensificando a instabilidade sobre o NEB como observaram Bastos \& Ferreira (2000). Devem ser mencionados ainda os Vórtices Ciclônicos de Altos Níveis (VCAN), (Gan \& Kousky, 1986; Rao \& Bonatti, 1987). Além dos VCANs, podem ser observados Vórtices Ciclônicos de Médios Níveis (VCMN) na qual afetam muito a mudança do tempo no NEB. Os VCMNs apresentam circulação ciclônicas, e são observados somente em médios níveis, exatamente entre 700 a $400 \mathrm{hPa}$, associados aos sistemas frontais no NEB originando precipitações intensas nessa região Fedorova (2008).

Como é esperado, a região do Sertão sendo a região mais árida do Estado apresentou ETo superiores as demais regiões. Resultado da forte isolação, temperaturas altas e escassez de chuvas nessa região (Brito et al., 2007).

As diferenças na demanda evaporativa, ou melhor, de evapotranspiração entres as regiões, deve-se as taxas de umidade retida pela atmosfera nessas regiões, sendo as regiões localizadas perto do oceano com teor de umidade mais elevadas em relação as mais afastadas. Assim, como mostrado por Allen et al. (1998) e Ligia et al. (2009), quanto mais próximo da saturação (umidade relativa $100 \%$ ) diminui a quantidade de vapor d'água que poderá ser retida na atmosfera fazendo assim reduzir a evapotranspiração da região. Outro aspecto importante, é a variação de temperatura com relação a altitude, regiões mais altas, normalmente apresentam temperaturas mais baixas, diminuindo assim a capacidade da atmosfera em reter calor ou vapor d'água resultante da evaporação da superfície e transpiração das plantas, devido a menor energia cinética das moléculas na atmosfera.

Os resultados observados para o período de retorno e as respectivas probabilidades, encontramse em inteira conformidade com os resultados observados acima de precipitação (Figura 1). Regiões com regime de chuvas baixa, com probabilidade baixa para o cultivo das culturas analisadas e período de retorno relativamente alto. $\mathrm{E}$ regiões com chuvas mais elevadas com maiores probabilidades de êxito e com período de retorno baixo, ou seja, anual.

\section{Conclusão}

A região do Sertão não apresenta disponibilidade hídrica na estação de cultivo favorável para o cultivo de milho, arroz, tomate, feijão e batata, com exceção de Água Branca, que apresenta condições favoráveis para o cultivo do feijão. Isto implica na necessidade de implementação de sistemas de irrigação para o melhoramento da produtividade agrícola.

Quanto às demais regiões do estado, verificou-se a existência de condições favoráveis para o cultivo destas culturas. A exceção foi o cultivo de tomate, que não apresentou condições para quase todas as regiões, destacando-se apenas favorável para Maceió e Porto de Pedras, com período de retorno anual.

É importante a implementação de sistemas de irrigação para um melhor desenvolvimento das culturas com necessidade hídrica acima de $600 \mathrm{~mm}$ em todo o Estado de Alagoas.

\section{Agradecimentos}

Os autores agradecem ao Conselho Nacional de Desenvolvimento Científico e Tecnológico $(\mathrm{CNPq})$ e à Fundação de Amparo à Pesquisa do Estado de Alagoas (FAPEAL). 


\section{Referências}

ALLEN, R. G. 1986. A Penman for all season. Rome: FAO. Irrigation and Drainage Paper, v. 112, n. 4 , p. $348-368$.

ALLEN, R. G.; PEREIRA, L. S.; RAES, D.; SMITH, M. 1998. Crop evapotranspiration: Guidelines for computing crop water requirements. Rome: FAO. Irrigation and Drainage Paper, v. 56. FAO, 297p.

ALLEN, R. G.; SMITH, M.; PERREIRA, L. S.; PERREIRA, L. S. 1994. An update for the definition of reference evapotranspiration. ICID Bulletin, v. 43, p.1-34.

BASTOS, C.; FERREIRA, N. 2000. Análise climatológica da alta subtropical do atlântico sul. In: XI congresso brasileiro de meteorologia. Anais. Rio de Janeiro, pp. 612-619.

BERGONCI, J. I.; BERGAMASCHI, H.; SANTOS, A. O.; FRANÇA, S.; RADIN, B. 2001. Eficiência da irrigação em rendimento de grãos e matéria seca de milho. Pesquisa Agropecuária Brasileira, v. 36, p. 949-956.

BRITO, L. T. L.; MOURA, M. S. B.; GAMA, G. F. B. 2007. Potencialidades da água de chuva no Semi-Árido brasileiro. Embrapa Semi-Árido Petrolina-PE.

CARDIM, A. H. 2003. Caracterização da estação de cultivo em alagoas: análise temporal e espacial. Dissertação (Mestrado em Meteorologia), Instituto de Ciências Atmosféricas, Universidade Federal de Alagoas, 121p.

CHEN, M.; SHI, W.; XIE, P.; SILVA, V. B. S.; KOUSKY, V. E.; WAYNE HIGGINS, R.; JANOWIAK, J. E. 2008. Assessing objective techniques for gauge-based analyses of global daily precipitation. Journal of Geophysical Research, v. 113, D04110.

CROP WATER NEEDS: The influence of the climate on crop water needs. FAO, 2011. Disponível em: http://www.fao.org/docrep/s2022e/s2022e02.htm. Acesso em: 20 de abr. 2017.

DOORENBOS, J.; KASSAM, A. H. 1979. Yield Response to Water. FAO Irrigation and Drainage Paper. No. 33, FAO, Rome, Italy, 193p.

DOORENBOS, J.; PRUITT, W. O. 1977. Crop Water Requirements. FAO, 144p.
FEDOROVA, N. 2008. Sinótica III: frentes, correntes de jatos, ciclones e anticiclones. Universidade Federal de Alagoas (UFAL), Maceió-AL, 169p.

GAN, M. A.; KOUSKY, V. E. 1986. Vórtices ciclônicos da alta troposfera no oceano Atlântico Sul. Revista Brasileira de Meteorologia, n. 1, p. 1928.

LIGIA, S.; SOUZA, J. L.; AZEVEDO, C. A. V. 2009. Evapotranspiração e coeficiente de cultivo do tomate caqui cultivado em ambiente protegido. Revista Brasileira de Engenharia Agrícola e Ambiental, Campina Grande-PB, v. 13, n. 3, p. 289-296.

MOLION, L. C. B.; BERNARDO, S. 2002. Uma revisão da dinâmica das chuvas no Nordeste brasileiro. Revista Brasileira de Meteorologia, v. 17, p. 1-10.

MONTEIRO, J. E. B. A. (Org.). 2009. Agrometeorologia dos cultivos. $\mathrm{O}$ fator meteorológico na produção agrícola. 1. Ed. Brasília, DF: INMET, 530p.

MORIZET, J.; TOGOLA, D. 1984. Effect et arrière-effect de la sécheresse sur la croissance de plusieurs génotipes de maïs. In: Conférence Internationale des Irrigations et du Drainage, 1984, Versailles. Les bésoins en eau des cultures. Paris: Inra, pp. 351-360.

OLIVEIRA, N. 2011. Análise da evolução de eventos extremos de precipitação diária na cidade de São Paulo. INMET-7 Disme/SP. Disponível em:

http://www.sbmet.org.br/sic2011/arq/7419382056 4147419382056.pdf. Acesso em: 10 de abr. 2017.

RAIMUNDO, C. C. 2011. Análise da probabilidade de ocorrência de extremos de precipitação e estudo da tendência de classes precipitação na região metropolitana de São Paulo. Dissertação (Mestrado em Meteorologia), Instituto de Ciências Atmosféricas, Universidade Federal de Alagoas, 133p.

RAO, V. B.; BONATTI, J. P. 1987. On the origin of upper tropospheric cyclonic vortices in the South Atlantic Ocean and adjoining Brazil during the summer. Meteorology and Atmospheric Physics, n. 37, p. 11-16.

SHEFFIELD, J.; GOTETI, GOPI.; WOOD, E. F. 2006. Development of a 50-Year High-Resolution 
Global Dataset of Meteorological Forcings for Land Surface Modeling. Journal of Climate, v. 19, p. 3088-3111.

SILVA, V. B. S.; KOUSKY, V. E.; SHI, W.; HIGGINS, R. W. 2007. An improved gridded historical daily precipitation analysis for Brazil. J. Hydrometeorol, v. 8, n. 4, p. 847-861.

SMITH, M. 1991. Report on the expert consultations on revision of FAO methodologies for crop water requirements. Rome: FAO, 45p.

SOUZA, J. L.; CARDIM, A. H.; CARVALHO, A. L.; LYRA, G. B.; SILVA, P. R. T.; ANTONIO, J.
F. 2015. Estação de cultivo em Alagoas baseada na precipitação pluvial, In: XXI Congresso Brasileiro de Agrometeorologia, 2015: O desafio do uso sustentável dos biomas brasileiros. Anais. LavrasMG, pp. 885-889.

TUCCI, C. E. M. 2002. Hidrologia-Ciência e

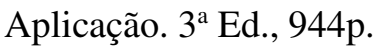

VAN BUUREN, S.; GROOTHUISOUDSHOORN K. 2011 Mice: Multivariate Imputation by Chained Equations. Journal of Statistical Software, v. 45, p. 1-67. 